\title{
Inhibition of CYFIP2 promotes gastric cancer cell proliferation and chemoresistance to 5-fluorouracil through activation of the Akt signaling pathway
}

\author{
SHUHUA JIAO, NUO LI, SHUANG CAI, HAIMEI GUO and YANHUI WEN \\ Department of Gastroenterology, The Fourth Affiliated Hospital of China Medical University, \\ Shenyang, Liaoning 110032, P.R. China
}

Received January 25, 2016; Accepted December 6, 2016

DOI: $10.3892 / \mathrm{ol} .2017 .5743$

\begin{abstract}
Gastric cancer is a common gastrointestinal malignancy that accounts for a notable proportion of cancer-associated mortalities worldwide. Cytoplasmic fragile $\mathrm{X}$ mental retardation 1-interacting protein 2 (CYFIP2) is a novel p53-mediated pro-apoptotic protein whose expression is decreased in gastric cancer. However, whether decreased expression of CYFIP2 contributes to gastric carcinogenesis remains unclear. In order to mimic in vivo gastric tumor CYFIP2 expression levels, the present study used short hairpin RNA targeting CYFIP2 mRNA to silence CYFIP2 expression in MGC803 and SGC7901 gastric cancer cells. Gastric cancer cells with constitutively decreased CYFIP2 expression levels were successfully established. It was observed that CYFIP2 knockdown promoted proliferation and colony formation, and inhibited apoptosis in these cells. Furthermore, 5-fluorouracil (5-FU)-induced apoptosis was decreased following inhibition of CYFIP2 expression. In SGC7901 cells, protein expression of active caspase- 3 and cleaved poly (ADP-ribose) polymerase was increased following treatment with 5-FU, while phosphorylated Akt serine/threonine kinase 1 (Akt) levels were decreased. These 5-FU-induced effects were reduced following CYFIP2 knockdown. In addition, inhibition of the Akt signaling pathway using the Akt inhibitor LY294002 restored CYFIP2-knockdown SGC7901 cell chemosensitivity to 5-FU. The results of the present study demonstrate that decreased CYFIP2 expression is associated with increased gastric tumor growth in vitro and that CYFIP2 knockdown-induced activation of the Akt pro-survival signaling pathway confers
\end{abstract}

Correspondence to: Dr Yanhui Wen, Department of Gastroenterology, The Fourth Affiliated Hospital of China Medical University, 4 East Chongshan Road, Shenyang, Liaoning 110032, P.R. China

E-mail: yanhuiwen1122@163.com

Key words: cytoplasmic fragile $\mathrm{X}$ mental retardation 1-interacting protein 2, gastric cancer, proliferation, chemoresistance, Akt serine/threonine kinase 1 signaling pathway resistance to 5-FU-based chemotherapy in gastric cancer cells. Therefore, combined treatment with an Akt inhibitor and chemotherapeutic drugs may improve the efficacy of gastric cancer therapy in patients with low CYFIP2 expression.

\section{Introduction}

Gastric cancer accounts for a considerable proportion of cancer-associated morbidity and mortality worldwide (1), and the incidence of this malignancy is higher in developing countries (2). Gastric cancer incidence and mortality has declined in previous decades, which is due in part to a reduction in smoking and the improved treatment of Helicobacter pylori infection $(1,3)$. However, the prognosis of patients with advanced stage gastric cancer remains poor (4). The identification of novel molecules associated with gastric carcinogenesis is required to improve gastric cancer treatments.

Cytoplasmic fragile X mental retardation (FMR) 1-interacting protein 2 (CYFIP2) is a homologue of CYFIP1, a protein that is capable of interacting with all FMR proteins (5). CYFIP2, also known as p53-inducible protein 121, is a protein with unknown functional domains and structural motifs. The majority of CYFIP2 studies focused on its functional role in fragile $\mathrm{X}$ syndrome, a common form of inherited intellectual disability and autism $(5,6)$. However, whether CYFIP2 is associated with carcinogenesis remains to be elucidated. CYFIP2 was reported to be a candidate p53 target gene by Saller et al (7) in H1299 lung cancer cells and this was validated by Jackson et al (8) in DLD1 colorectal adenocarcinoma cells. CYFIP2 overexpression was not demonstrated to induce apoptosis in lung cancer cells (7); however, CYFIP2 overexpression promoted apoptotic-like death in colorectal cancer cells (8). The former study (7) suggested that CYFIP2-induced apoptosis is part of a coordinated p53-dependent response in cancer cells, while the latter study (8) suggested that CYFIP2 itself functions as a pro-apoptotic protein. CYFIP2 mRNA expression has been demonstrated to be significantly decreased in gastric cancer tissues compared with non-cancerous tissues (9). In the present study, the association between decreased CYFIP2 expression and gastric carcinogenesis was investigated, and the potential underlying mechanisms were examined. 
In order to mimic the gastric tumor microenvironment in vivo, RNA interference (RNAi) was used to suppress endogenous CYFIP2 expression in the gastric cancer cell lines MGC-803 and SGC-7901. Antitumor drug-based cytotoxic chemotherapy is routinely administered to the majority of patients with advanced gastric cancer (10); however, the development of chemoresistance is common, which leads to treatment failure (11). To investigate the potential association between decreased CYFIP2 expression and chemoresistance in gastric cancer cells, gastric cancer cell proliferation and apoptosis following treatment with or without 5-fluorouracil (5-FU) was determined.

\section{Materials and methods}

Cell culture. The human gastric cancer cell lines MGC803 and SGC7901 were obtained from the Type Culture Collection of the Chinese Academy of Sciences (Shanghai, China). Cells were cultured in Dulbecco's modified Eagle's medium (Gibco; Thermo Fisher Scientific, Inc., Waltham, MA, USA) containing 10\% fetal bovine serum (HyClone; GE Healthcare, Logan, UT, USA), $100 \mu \mathrm{g} / \mathrm{ml}$ streptomycin and $100 \mathrm{U} / \mathrm{ml}$ penicillin. Cells were cultured at $37^{\circ} \mathrm{C}$ in a humidified atmosphere containing $5 \% \mathrm{CO}_{2}$.

Stable transfection of gastric cancer cells with CYFIP2-tagerting short hairpin (sh)RNA. In order to inhibit CYFIP2 protein expression in the gastric cancer cells, the pRNA-H1.1 vector was purchased from GenScript (Nanjing, China) and used generate CYFIP2-targeting shRNA-expressing plasmids. A pair of oligonucleotides (sense, 5'-GATCCCCGG ACCTGCTTGAAGAGCTTTTCAAGAGAAAGCTCTTCA AGCAGGTCCTTTTT-3' and antisense, 5'-AGCTAAAAA GGACCTGCTTGAAGAGCTTTCTCTTGAAAAGCTCTT CAAGCAGGTCCGGG-3') targeting CYFIP2 mRNA were synthesized by Sangon Biotech Co., Ltd. (Shanghai, China) and inserted into the pRNA-H1.1 expression vector. The CYFIP2-targeting shRNA targeted the sequence 5'-GGACCT GCTTGAAGAGCTT-3'. The oligonucleotides were initially allowed to anneal to form a DNA duplex, with cohesive ends containing a BamHI and HindIII site. A total of $2 \mu \mathrm{g}$ empty pRNA-H1.1 vector was digested using $2.5 \mu \mathrm{BamHI}$ and $2.5 \mu 1$ HindIII (both Fermentas; Thermo Fisher Scientific, Inc.) in a $50 \mu 1$ system for $30 \mathrm{~min}$ at $37^{\circ} \mathrm{C}$. The plasmids were subsequently incubated with the CYFIP2 shRNA and $1 \mu \mathrm{l} 4$ DNA ligase (Takara Biotechnology Co., Ltd., Dalian, China) at $16^{\circ} \mathrm{C}$ overnight, according to the manufacturer's protocol. Plasmids containing scrambled shRNA (sense, 5'-GATCCC CTTCTCCGAACGTGTCACGTTTCAAGAGAACGTGAC ACGTTCGGAGAATTTTT-3' and antisense, 5'-AGCTAA AAATTCTCCGAACGTGTCACGTTCTCTTGAAACGTG ACACGTTCGGAGAAGGG-3') were used as a negative control. The constructed plasmids were transfected into gastric cancer cells using Lipofectamine ${ }^{\circledR} 2000$ (Invitrogen; Thermo Fisher Scientific, Inc.), according to the manufacturer's protocol. Following transfection, cells were treated with $400 \mu \mathrm{g} / \mathrm{ml}$ G418 (Invitrogen; Thermo Fisher Scientific, Inc.) for between 1 and 2 weeks to select for successfully transfected cells expressing CYFIP2 shRNA or scrambled shRNA. Reverse transcription-quantitative polymerase chain reaction (RT-qPCR) and western blot analyses were performed using the G418-resistant clones, as described below, to determine CYFIP2 mRNA and protein expression, respectively. The cell clone from each gastric cancer cell line with the lowest CYFIP2 expression was used for subsequent analysis.

Cell Counting Kit-8 (CCK-8) and colony formation assay. The CCK-8 was purchased from Beyotime Institute of Biotechnology (Haimen, China) and was used to determine cell proliferation rates. Following trypsinization (Sigma-Aldrich; Merck Millipore, Darmstadt, Germany), cells were seeded into 96-well plates at a density of $2 \times 10^{3}$ cells/well $(n=5)$, and cultured for $24,48,72$ and $96 \mathrm{~h}$ at $37^{\circ} \mathrm{C}$. A total of $10 \mu \mathrm{lCCK}-8$ solution in $100 \mu \mathrm{l}$ culture medium was added into each well at each time point for $1 \mathrm{~h}$ and the absorbance was measured at a wavelength of $450 \mathrm{~nm}$.

For the colony formation assay, 100 cells were seeded into sterile $35-\mathrm{mm}$ dishes and cultured at $37^{\circ} \mathrm{C}$ for 14 days. The culture medium was replaced every 3 days. Cell colonies were subsequently fixed using $4 \%$ paraformaldehyde for $20 \mathrm{~min}$ at room temperature (RT), incubated with Wright-Giemsa stain (Nanjung Jiancheng Bioengineering Institute, Nanjing, China) for between 5-8 min at RT, and counted using a light microscope $(n=3)$. Colony formation was determined as the ratio of the number of colonies:number of cells seeded.

Apoptosis assay. Cell apoptosis was assessed using a flow cytometer. Certain gastric cancer cells were treated with $25 \mu \mathrm{M}$ LY294002 (Beyotime Institute of Biotechnology). Cells $\left(1 \times 10^{5}\right)$ were treated with $15 \mu \mathrm{g} / \mathrm{ml} 5$-FU (Sigma-Aldrich; Merck Millipore) for $24 \mathrm{~h}$ at $37^{\circ} \mathrm{C}$. Following treatment with 5-FU, cells were trypsinized ( $0.2 \%$; Thermo Fisher Scientific, Inc.) and centrifuged at $309 \times g$ for $5 \mathrm{~min}$ at $4^{\circ} \mathrm{C}$, prior to the addition of $500 \mu$ l binding buffer (Nanjing KeyGen Biotech Co., Ltd., Nanjing, China). Cells were subsequently cultured with $5 \mu \mathrm{l}$ Annexin V-fluorescein isothiocyanate (FITC) and $5 \mu 1$ propidium iodide (PI) (both Nanjing KeyGen Biotech Co., Ltd.) for $15 \mathrm{~min}$ in the dark at RT. Apoptotic cells were identified using flow cytometry and BD Accuri C6 software (BD Biosciences, San Jose, CA, USA).

RT-qPCR. Total cellular RNA was prepared using a Fast RNApure Extraction kit (BioTek Instruments, Inc., Winooski, VT, USA). Extracted RNA was reverse transcribed into first-strand cDNA using Super Moloney murine leukemia virus reverse transcriptase (BioTek Instruments, Inc.) under the following temperature conditions: $25^{\circ} \mathrm{C}$ for $10 \mathrm{~min} ; 42^{\circ} \mathrm{C}$ for $50 \mathrm{~min}$; and $95^{\circ} \mathrm{C}$ for $5 \mathrm{~min}$ to terminate the reaction. The following CYFIP2 primers were used in PCR analysis: Forward, 5'-TCCGTATCCACCGTCCA AT-3'; and reverse, 5'-AATCTCCAGCAGCCACTCC-3'. qPCR was performed using the $\mathrm{SYBR}^{\circledR}$ Green Master mix (Beijing Solarbio Science \& Technology Co., Ltd., Beijing, China). The following thermocycling conditions were used: $94^{\circ} \mathrm{C}$ for $10 \mathrm{~min}$; 40 cycles of $94^{\circ} \mathrm{C}$ for $10 \mathrm{sec}, 60^{\circ} \mathrm{C}$ for $20 \mathrm{sec}$ and $72^{\circ} \mathrm{C}$ for $30 \mathrm{sec}$; $72^{\circ} \mathrm{C}$ for $2.5 \mathrm{~min} ; 40^{\circ} \mathrm{C}$ for $5.5 \mathrm{~min}$; temperature was increased from 60 to $94^{\circ} \mathrm{C}$ at a rate of $1^{\circ} \mathrm{C} / \mathrm{sec}$; and $25^{\circ} \mathrm{C}$ for $1 \mathrm{~min}$. The relative expression levels of CYFIP2 were calculated using the $2^{-\Delta \Delta C q}$ method (12), with $\beta$-actin used as the endogenous control. The $\beta$-actin primer sequences were as follows: Forward, 5'-CCA TCGTCCACCGCAAAT-3' and reverse, 5'-GCTGTCACCTTC ACCGTTC-3'. 
A

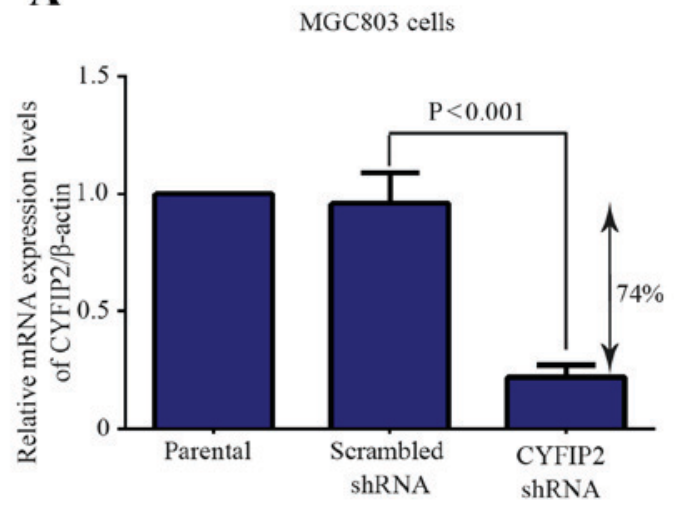

C
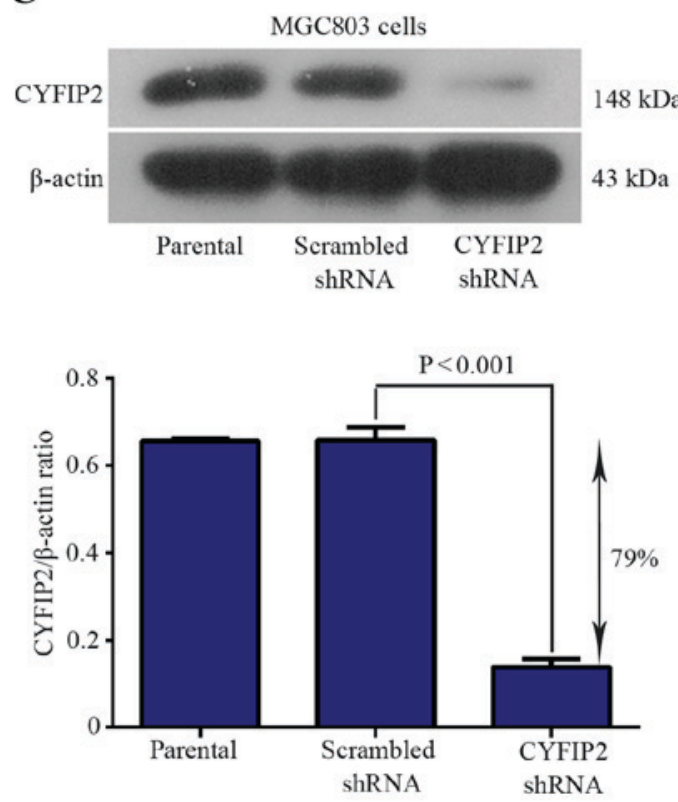

B

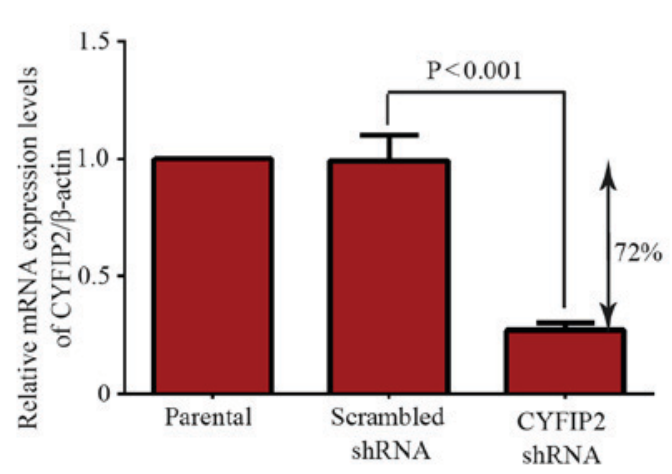

D
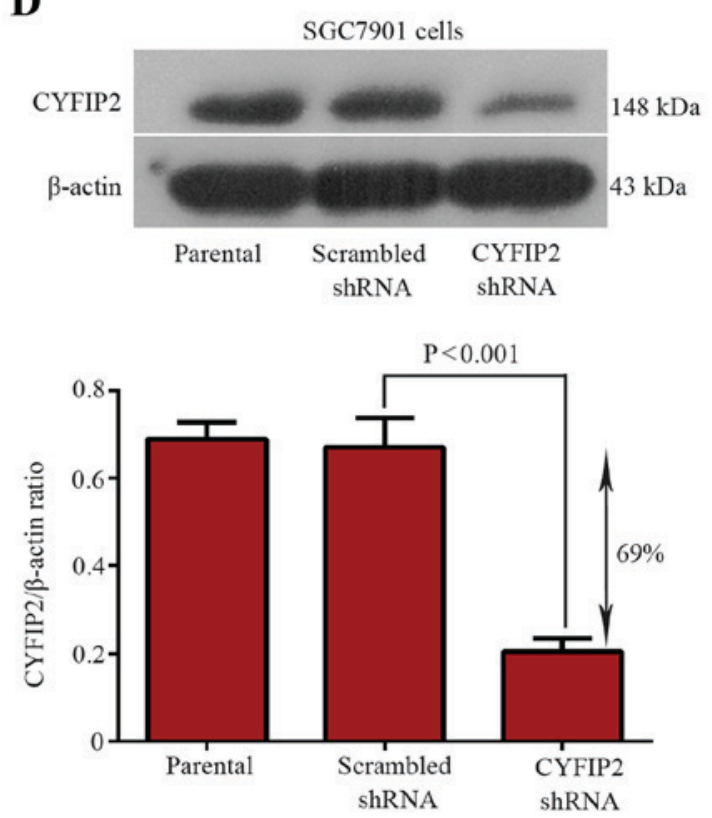

Figure 1. Evaluation of the knockdown efficiency of CYFIP2 following shRNA transfection. CYFIP2 mRNA expression levels in (A) MGC803 and (B) SGC7901 cells. CYFIP2 protein expression levels in (C) MGC803 and (D) SGC7901 cells. Values were normalized to endogenous $\beta$-actin mRNA and protein expression, respectively. Results are presented as the mean \pm standard deviation $(n=3)$. CYFIP2, cytoplasmic fragile X mental retardation 1-interacting protein 2; shRNA, short hairpin RNA.

Western blot analysis. Total cellular protein was prepared using radioimmunoprecipitation assay buffer and quantified using the BCA Protein Assay kit (both Beyotime Institute of Biotechnology). Total protein samples $(30 \mu \mathrm{g})$ were separated using SDS-PAGE on a $10 \%$ gel and transferred onto polyvinylidene difluoride membranes. Membranes were blocked with 5\% (w/v) non-fat milk for $1 \mathrm{~h}$ at RT. Membranes were subsequently incubated with primary rabbit polyclonal antibodies against CYFIP2 (1:500; cat. no. bs-7606R; Bioss, Beijing, China), active caspase-3 (1:1,000; cat. no. ab2302), cleaved poly (ADP-ribose) polymerase (PARP; 1:1,000; cat. no. ab32561 (both Abcam, Cambridge, UK), phosphorylated Akt serine/threonine kinase 1 (p-Akt; 1:200; cat. no. sc-135651), Akt (1:200; cat. no. sc-8312) and $\beta$-actin (1:1,000; cat. no. sc-47778; all Santa Cruz Biotechnology, Inc., Dallas, TX, USA) overnight at $4^{\circ} \mathrm{C}$. Membranes were then incubated with goat anti-rabbit horseradish peroxidase (HRP)-labeled immunoglobulin (Ig)G (1:5,000; cat. no. A0208; Beyotime Institute of Biotechnology) or goat anti-mouse HRP-labeled IgG (1:5,000; cat. no. A0216; Beyotime Institute of Biotechnology) for $45 \mathrm{~min}$ at $37^{\circ} \mathrm{C}$.
Protein bands were visualized using an enhanced chemiluminescence kit (Shanghai Seven Sea Pharmtech Company, Shanghai, China) and band densities were normalized to endogenous $\beta$-actin expression. Bands were quantified using Gel-Pro Analyzer software (version 4.0; Media Cybernetics, Inc., Rockville, MD, USA).

Statistical analysis. Values are presented as the mean \pm standard deviation of triplicate experiments. All data were analyzed using SPSS software (version 20.0; IBM SPSS, Armonk, NY, USA). Where appropriate, an unpaired $t$-test was performed to compare data between two groups. A nonparametric test was performed to compare datasets with unequal variances. $\mathrm{P}<0.05$ was considered to indicate a statistically significant difference.

\section{Results}

Evaluation of the knockdown efficiency of CYFIP2 ShRNA in gastric cancer cells. To evaluate the role of CYFIP2 in gastric 
A

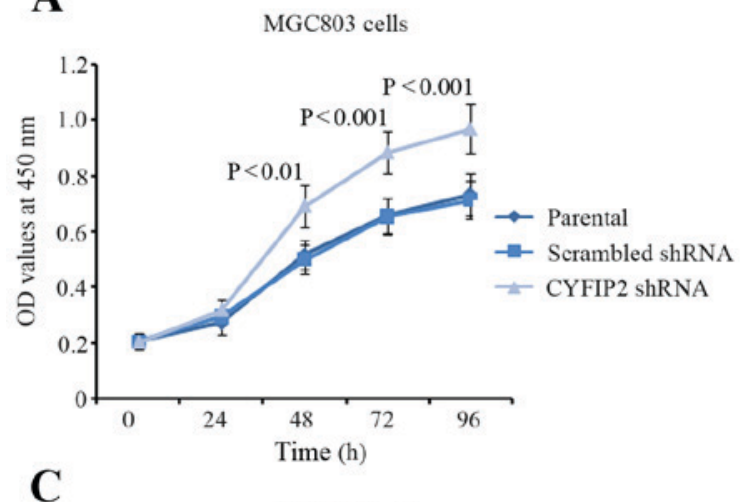

C
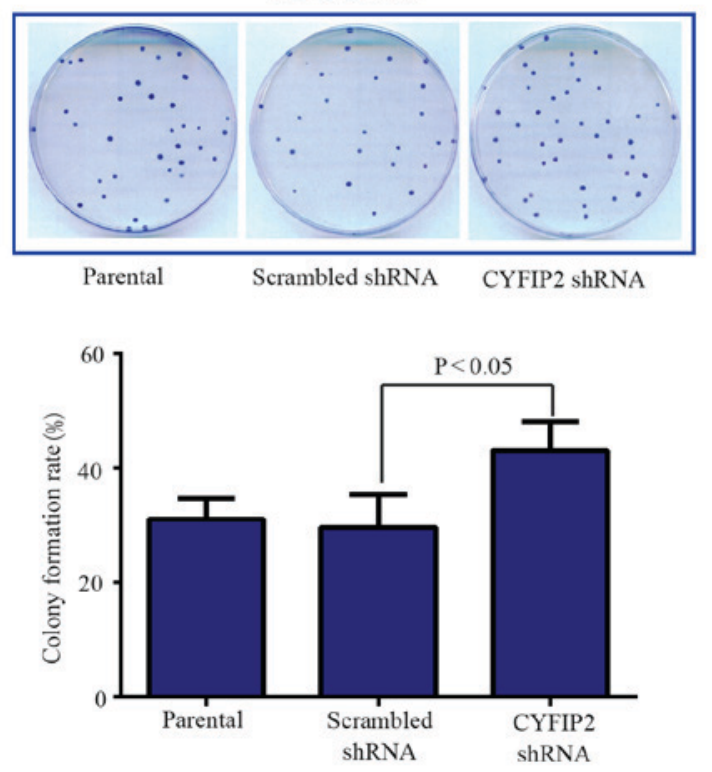

B

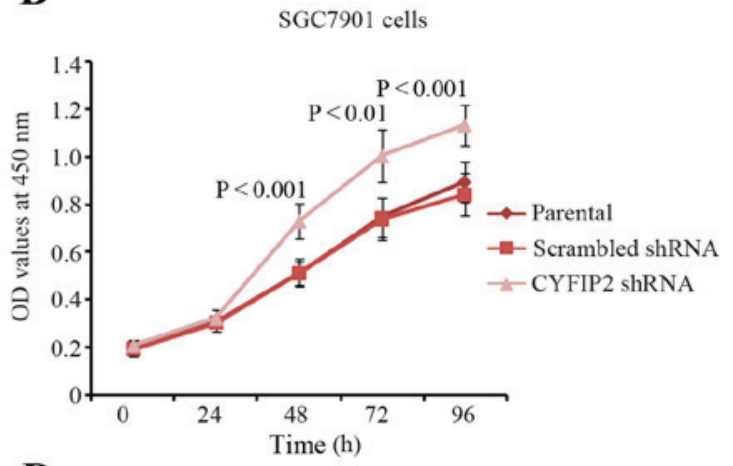

D
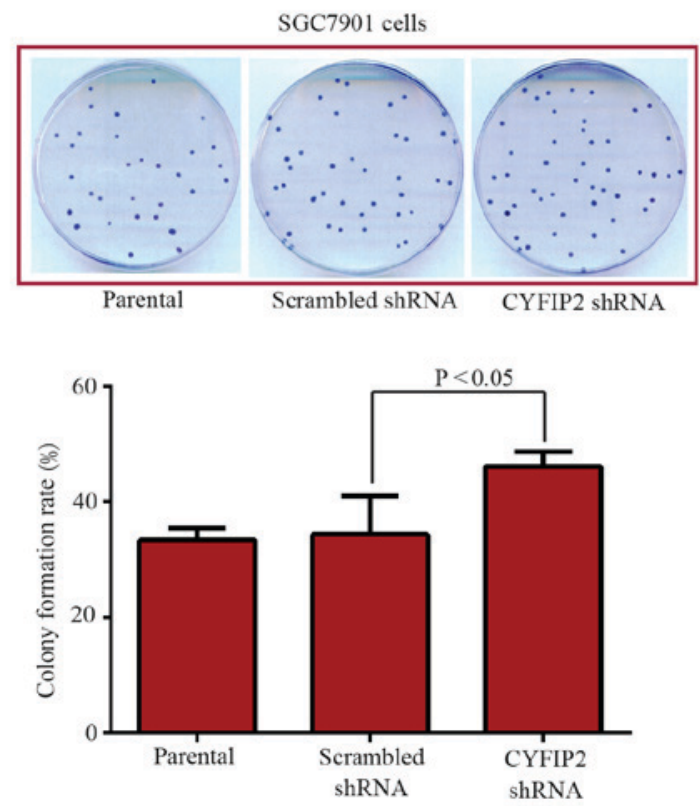

Figure 2. CYFIP2 inhibition promotes gastric cancer cell growth in vitro. (A) MGC803 and (B) SGC7901 cell proliferation was significantly increased following CYFIP2 knockdown ( $\mathrm{n}=5$ ). (C) MGC803 and (D) SGC7901 colony formation was significantly increased following CYFIP2 knockdown ( $\mathrm{n}=8$ ). Results are presented as the mean \pm standard deviation. CYFIP2, cytoplasmic fragile X mental retardation 1-interacting protein 2; shRNA, short hairpin RNA.

tumorigenesis, RNAi experiments using a CYFIP2 shRNA were performed in two gastric cancer cell lines. The knockdown efficiency of the CYFIP2 shRNA was determined by evaluating CYFIP2 mRNA and protein expression using RT-qPCR and western blotting, respectively. CYFIP2 mRNA expression was significantly decreased by $74 \%$ in MGC803 cells following CYFIP2 shRNA transfection compared with the scrambled shRNA group ( $\mathrm{P}=0.0008$; Fig. 1A). CYFIP2 mRNA expression was significantly decreased by $72 \%$ in SGC7901 cells following CYFIP2 shRNA transfection compared with the scrambled shRNA group $(\mathrm{P}<0.0001$; Fig. 1B). CYFIP2 protein expression was significantly decreased by $79 \%$ in MGC803 cells following CYFIP2 shRNA transfection compared with the scrambled shRNA group ( $\mathrm{P}<0.0001$; Fig. 1A). CYFIP2 protein expression was significantly decreased by $69 \%$ in SGC7901 cells following CYFIP2 shRNA transfection compared with the scrambled shRNA group ( $\mathrm{P}=0.0004$; Fig. 1A). These results suggest that gastric cancer cells with decreased CYFIP2 expression levels were successfully established.

Silencing of CYFIP2 suppresses gastric cancer cell proliferation and colony formation. Cell proliferation was determined using the CCK-8 assay. Cell proliferation rates were significantly increased in MGC803 ( $\mathrm{P}=0.0016$; Fig. 2A) and SGC7901 $(\mathrm{P}=0.0005$; Fig. 2B) cells from $48 \mathrm{~h}$ following CYFIP2 shRNA transfection compared with their respective scrambled shRNA-transfected groups. Furthermore, rates of MGC803 $(\mathrm{P}=0.038)$ and SGC7901 $(\mathrm{P}=0.0478)$ cell colony formation were significantly increased following CYFIP2 shRNA transfection compared with the scrambled shRNA-transfected groups (Fig. 2C and D). These results demonstrate that CYFIP2 silencing contributes to gastric cancer cell proliferation in vitro.

Knockdown of CYFIP2 inhibits gastric cancer cell apoptosis and induces resistance to 5-FU. Cell apoptosis was evaluated using flow cytometric analysis of Annexin V-FITC/PI stained cells. In the absence of 5-FU, CYFIP2 knockdown significantly decreased the apoptotic percentage of MGC803 cells from $15.00 \pm 1.71$ in the scrambled shRNA-transfected control cells to $6.13 \pm 0.58 \%(\mathrm{P}=0.001$; Fig. $3 \mathrm{~A}$ and $\mathrm{B})$. Similarly, CYFIP2 knockdown significantly decreased the apoptotic percentage of SGC7901 cells from $14.26 \pm 1.53$ in the scrambled shRNA-transfected control cells to $3.54 \pm 0.51 \%(\mathrm{P}=0.0003$; Fig. 3A and C). Evasion of apoptosis is an essential component 
A
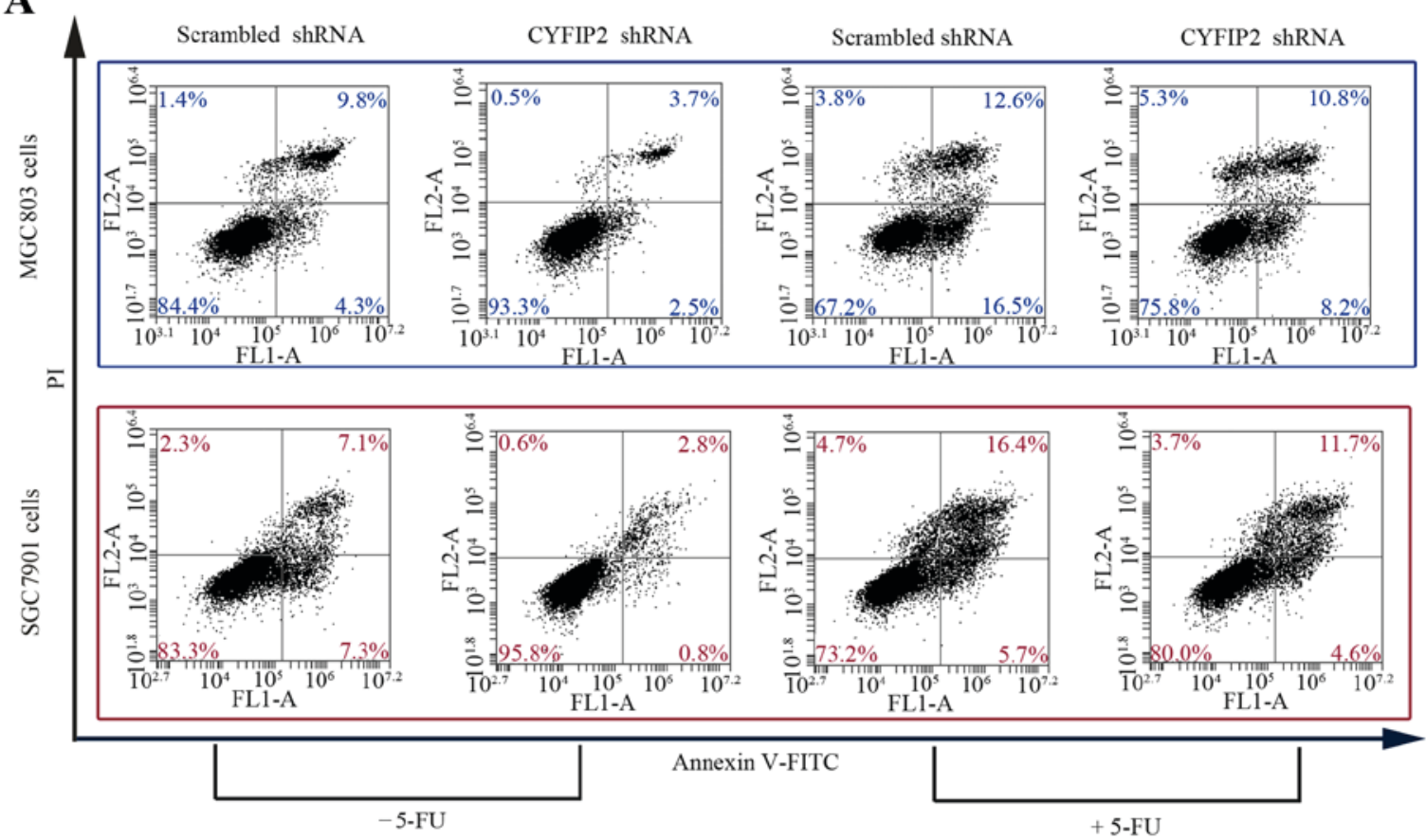

B

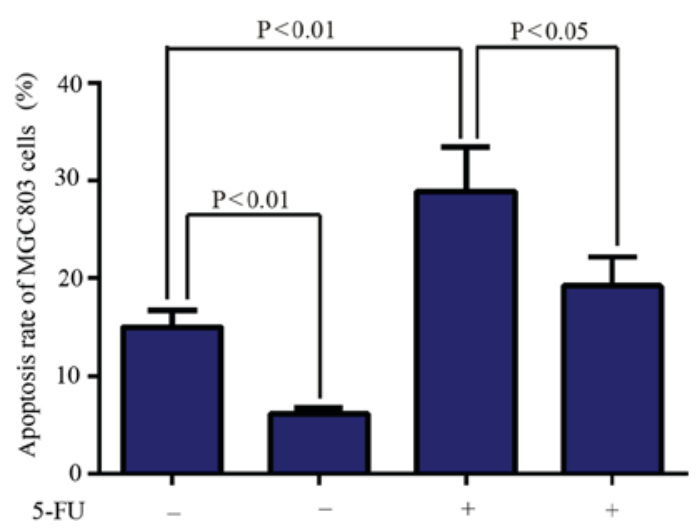

Scrambled shRNA +

CYFIP2 shRNA

C

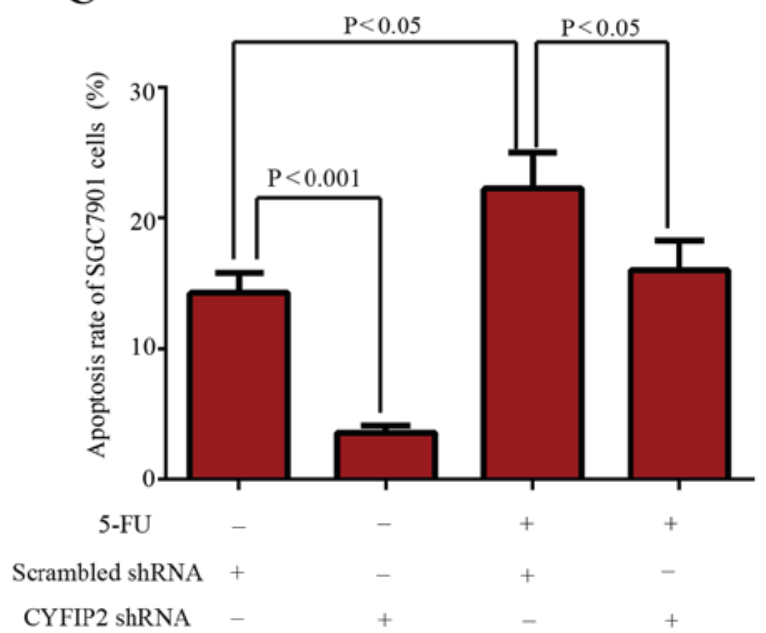

Figure 3. CYFIP2 knockdown induces 5-FU-resistance in gastric cancer cells in vitro. (A) MGC803 and SGC7901 cell apoptosis was quantified using flow cytometric analysis. The apoptotic cell ratio was calculated as the sum of the lower and upper right quadrants of the flow cytometric data for (B) MGC803 and (C) SGC-7901 cells. Results are presented as the mean \pm standard deviation (n=3). CYFIP2, cytoplasmic fragile X mental retardation 1-interacting protein 2; 5-FU, 5-fluorouracil; shRNA, short hairpin RNA; FL, fluorescence; A, area; PI, propidium iodide; FITC, fluorescein isothiocyanate.

of the chemoresistance of cancer cells (13). Subsequently, the effect of CYFIP2 knockdown on the response of gastric cancer cells to 5-FU was subsequently investigated. Treatment with 5-FU induced significantly increased apoptosis in MGC803 ( $\mathrm{P}=0.0073$; Fig. 3B) and SGC7901 (P=0.0118; Fig. 3C) cells compared with the cells that did not receive 5-FU treatment. However, the cytotoxic effect of treatment with 5-FU was significantly decreased by CYFIP2 knockdown in MGC803 ( $\mathrm{P}=0.0353$; Fig. 3B) and SGC7901 ( $\mathrm{P}=0.04$; Fig. 3C) cells compared with the scrambled shRNA-transfected group. These data indicate that inhibition of CYFIP2 contributes to the development of resistance to 5-FU in gastric cancer cells.

Akt serine/threonine kinase 1 (Akt) inhibition restores the 5-FU chemosensitivity of CYFIP2-knockdown SGC-7901 cells.
Aberrant activation of the Akt signaling pathway is associated with tumorigenesis and chemoresistance in various types of cancer (14). The phosphorylation status of Akt in SGC-7901 cells was evaluated using western blotting following CYFIP2 knockdown and treatment with 5-FU. While total Akt protein expression remained unchanged in the SGC-7901 cells treated with the scrambled shRNA, phosphorylated (p)-Akt expression was decreased $12 \mathrm{~h}$ following treatment with 5 -FU in a time-dependent manner (Fig. 4A and B). CYFIP2-knockdown SGC-7901 cells exhibited significantly increased p-Akt expression following treatment with 5-FU compared with the scrambled shRNA-transfected group at all time points (all $\mathrm{P}<0.05$; Fig. 4A and B). Furthermore, the expression of cleaved caspase-3 and cleaved PARP were determined in SGC-7901 cells. 5-FU-induced upregulation of cleaved caspase-3 and 

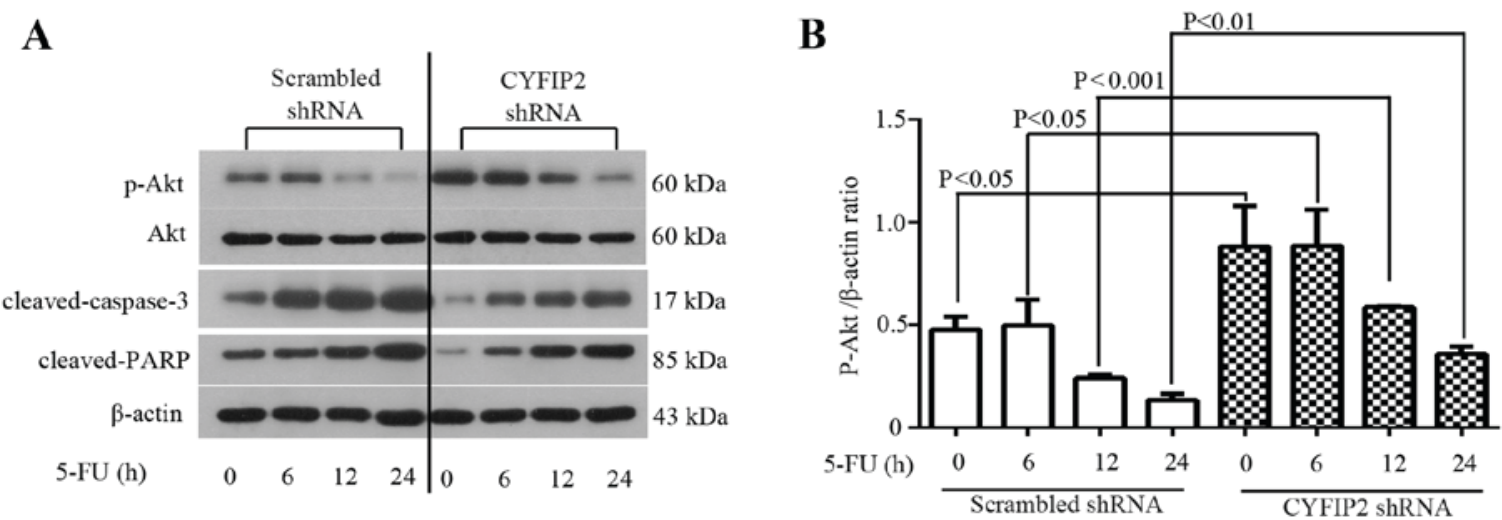

C
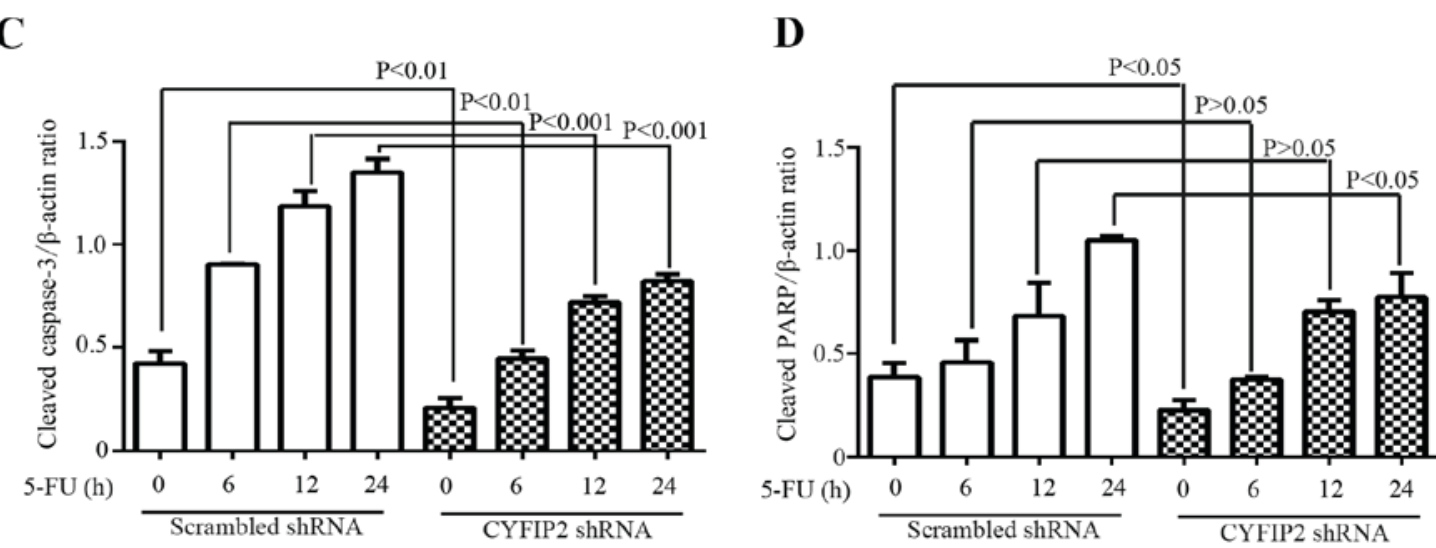

$\mathbf{E}$
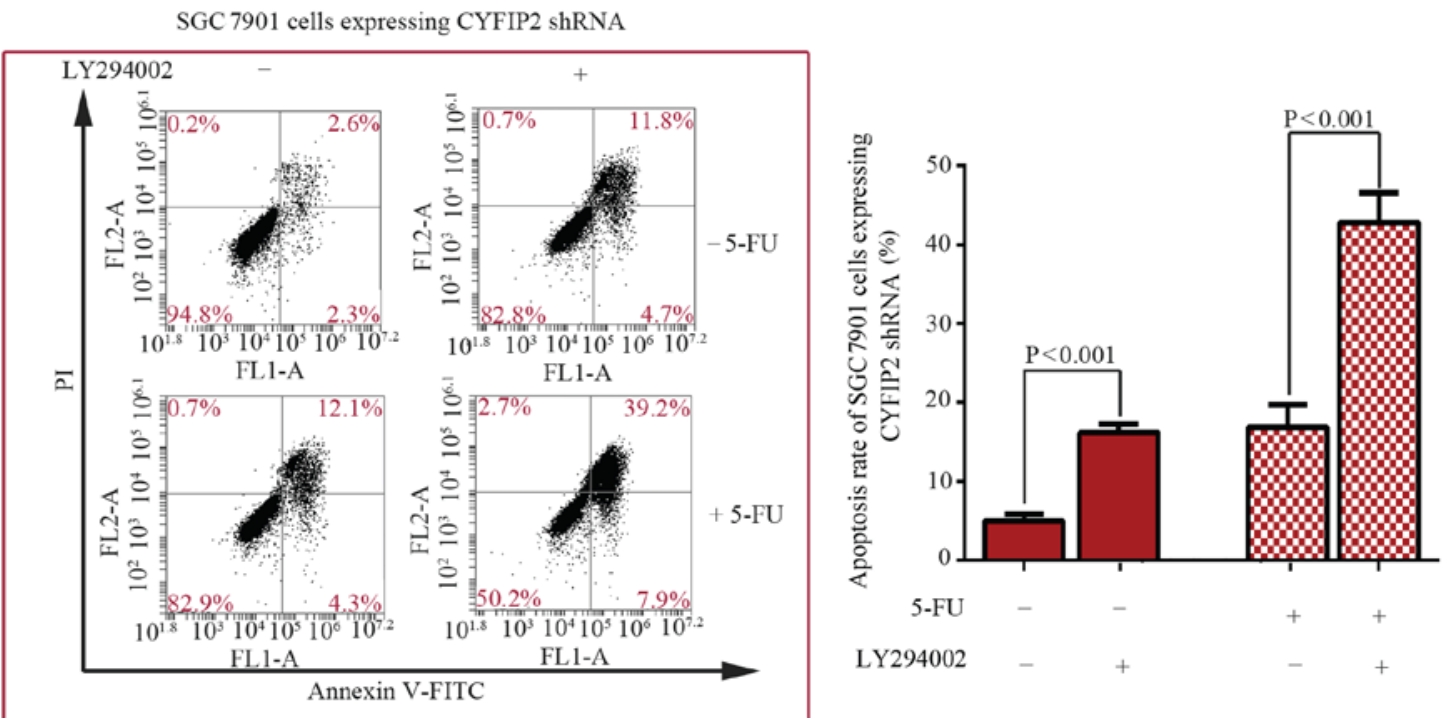

LY294002

Figure 4. Akt inhibitor LY294002 restores the chemosensitivity of CYFIP2-deficient SGC7901 cells to 5-FU. (A) Western blot analysis of p-Akt, Akt, active caspase-3 and cleaved PARP protein expression SGC7901 cells following CYFIP2 knockdown and treatment with 5-FU. Quantification of (B) p-Akt, (C) cleaved caspase-3 and (D) cleaved PARP protein bands. Values were normalized to $\beta$-actin. (E) SGC7901 cell apoptosis was quantified using flow cytometric analysis following treatment with LY294002. Results are presented as the mean \pm standard deviation $(\mathrm{n}=3)$. Akt, Akt serine/threonine kinase 1; CYFIP2, cytoplasmic fragile X mental retardation 1-interacting protein 2; 5-FU, 5-fluorouracil; p, phosphorylated; PARP, poly (ADP-ribose) polymerase; shRNA, short hairpin RNA; FL, fluorescence; A, area; PI, propidium iodide; FITC, fluorescein isothiocyanate.

PARP protein expression was significantly inhibited by CYFIP2 knockdown $(\mathrm{P}<0.05$ vs. the scrambled shRNA-transfected group; Fig. 4A, C and D). To confirm whether activation of the Akt signaling pathway was associated with CYFIP2 knockdown-induced chemoresistance in SGC-7901 cells, the potent Akt inhibitor LY294002 was used. The results of the apoptosis assay performed demonstrated that treatment with LY294002 significantly increased the apoptosis of CYFIP2-knockdown cells in the presence $(\mathrm{P}=0.0002)$ and absence $(\mathrm{P}=0.0007)$ of 5-FU (Fig. 4E). These results indicate that inhibition of the Akt signaling pathway restores the chemosensitivity of CYFIP2-knockdown gastric cancer cells to 5-FU. 


\section{Discussion}

Gastric cancer cells exhibit increased proliferation during carcinogenesis (15). A previous study revealed that CYFIP2 expression is decreased in gastric cancer tissues (9). However, whether this low expression of CYFIP2 is associated with gastric carcinogenesis remains to be elucidated. In the present study, CYFIP2 expression was suppressed in two gastric cancer cell lines in vitro through shRNA-mediated knockdown. It was observed that CYFIP2 knockdown promoted the proliferation and survival of malignant clones in the MGC-803 and SGC-7901 cell lines. Constitutive activation of the oncogenic protein GTPase KRas (K-Ras) occurs frequently in human cancer, including gastric cancer $(16,17)$. A previous study identified that inducible and conditional activation of K-Ras resulted in the hyperproliferation of squamous epithelial cells in the forestomach of a mouse model and induced precancerous gastric lesions $(18,19)$. Another study demonstrated that CYFIP2 inhibition is able to increase K-Ras expression in colon cancer cells (20). The results of these studies and the present study indicate that CYFIP2 knockdown-induced gastric cancer cell proliferation is associated with increased K-Ras expression. Subsequently, the authors of the present study aim to investigate the in vivo association between CYFIP2 expression and K-Ras activation in gastric tumor samples in the future.

Evasion of apoptosis is an essential mechanism underlying carcinogenesis (21); however, stress-induced apoptosis has also been suggested to lead to tumor formation under certain circumstances (22). The ability to activate caspases, a group of apoptosis-inducing proteases, is a key mechanism used by potent anticancer drugs (23). The release of intermembrane proteins from the mitochondria, including cytochrome $c$, is able to promote the cleavage of caspase- 9 and subsequently induce activation of the essential apoptotic protein caspase-3, which leads to cell apoptosis (23). Overexpression of CYFIP2 can lead to enhanced activation of caspase- 3 and its downstream target PARP in colorectal cancer cells (8), suggesting that CYFIP2 is stimulates caspase activation in tumor cells. The results of the present study were consistent with the results of previous studies, in demonstrating that gastric SGC7901 cancer cells expressing CYFIP2-targeting shRNA exhibited decreased levels of active caspase-3 and cleaved PARP. Patients with gastric cancer are typically treated with DNA damage-inducing drugs (10). Chemotherapeutic regimes frequently induce cancer cell apoptosis through the activation of caspases (24). The present study demonstrated that treatment with 5-FU induced apoptosis, and promoted caspase-3 and PARP cleavage in gastric cancer cells. However, 5-FU-induced cytotoxicity was decreased in cells with decreased CYFIP2 expression. These results suggest that 5-FU chemoresistance in gastric cancer cells is associated with decreased CYFIP2 expression.

Akt is an essential effector of multiple signaling pathways, transducing downstream survival signals (25). Akt signaling is activated by phosphoinositide 3-kinase (26) and inhibited by the tumor suppressors p53 (27) and phosphatase and tensin homolog (28). CYFIP2 is a novel proapoptotic factor that is regulated by p53 (8). 5-FU initiates apoptosis in gastric tumor cells by activating the p53 signaling pathway (29) and inactivating the Akt signaling pathway (30). To the best of our knowledge, the present study was the first to demonstrate that 5-FU-induced Akt signaling inhibition was decreased by CYFIP2 knockdown in gastric cancers in vitro. The role of the Akt signaling pathway in the promotion of tumorigenesis has been studied previously; however, there is no evidence of functional crosstalk between CYFIP2 and Akt in gastric cancer. Notably, another p53-inducible protein, pleckstrin homology-like domain family A member 3, has been reported to compete with Akt for the binding of membrane lipids and therefore inhibit Akt activation (27). Thus, the association between CYFIP2 and Akt during gastric tumorigenesis requires further investigation in the future, via the ectopic overexpression of CYFIP2. The authors of the present study have also identified that BGC-823 gastric cancer cells exhibit decreased CYFIP2 expression (Jiao et al, unpublished data). CYFIP2 gain-of-function experiments in BGC-823 cells may assist in the elucidation of the role of CYFIP2 in gastric cancer development and progression.

In conclusion, the results of the present study demonstrate that inhibition of CYFIP2 contributes to the proliferation of gastric cancer cells in vitro. In addition, CYFIP2 knockdown-induced activation of the Akt pro-survival signaling pathway was revealed to confer resistance to 5-FU-based chemotherapy in gastric cancer cells. These results indicate that combination therapy with an Akt inhibitor and 5-FU may improve the efficacy of treatments for patients with gastric cancer who exhibit decreased CYFIP2 expression.

\section{Acknowledgements}

The present study was supported by the Science and Technology Project of Liaoning Province (grant no. 2010225032).

\section{References}

1. McLean MH and El-Omar EM: Genetics of gastric cancer. Nat Rev Gastroenterol Hepatol 11: 664-674, 2014.

2. Herrero R, Park JY and Forman D: The fight against gastric cancer-the IARC working group report. Best Pract Res Clin Gastroenterol 28: 1107-1114, 2014.

3. Peleteiro B, Bastos A, Ferro A and Lunet N: Prevalence of Helicobacter pylori infection worldwide: A systematic review of studies with national coverage. Dig Dis Sci 59: 1698-1709, 2014.

4. Shah MA and Ajani JA: Gastric cancer-an enigmatic and heterogeneous disease. JAMA 303: 1753-1754, 2010.

5. Schenck A, Bardoni B, Moro A, Bagni C and Mandel JL: A highly conserved protein family interacting with the fragile $\mathrm{X}$ mental retardation protein (FMRP) and displaying selective interactions with FMRP-related proteins FXR1P and FXR2P. Proc Natl Acad Sci USA 98: 8844-8849, 2001.

6. Hoeffer CA, Sanchez E, Hagerman RJ, Mu Y, Nguyen DV, Wong H, Whelan AM, Zukin RS, Klann E and Tassone F: Altered mTOR signaling and enhanced CYFIP2 expression levels in subjects with fragile X syndrome. Genes Brain Behav 11: 332-341, 2012.

7. Saller E, Tom E, Brunori M, Otter M, Estreicher A, Mack DH and Iggo R: Increased apoptosis induction by $121 \mathrm{~F}$ mutant $\mathrm{p} 53$. EMBO J 18: 4424-4437, 1999.

8. Jackson RS II, Cho YJ, Stein S and Liang P: CYFIP2, a direct p53 target, is leptomycin-B sensitive. Cell Cycle 6: 95-103, 2007.

9. Cheng AS, Li MS, Kang W, Cheng VY, Chou JL, Lau SS, Go MY, Lee CC, Ling TK, Ng EK, et al: Helicobacter pylori causes epigenetic dysregulation of FOXD3 to promote gastric carcinogenesis. Gastroenterology 144: 122-133, e9, 2013.

10. Liu R, Huang M, Zhao X, Peng W, Sun S, Cao J, Ji D, Wang C, Guo W and Li J, et al: Neutropenia predicts better prognosis in patients with metastatic gastric cancer on a combined epirubicin, oxaliplatin and 5-fluorouracil regimen. Oncotarget 6: 39018-39027, 2015. 
11. Bain GH, Collie-Duguid E, Murray GI, Gilbert FJ, Denison A, McKiddie F, Ahearn T, Fleming I, Leeds J, Phull P, et al: Tumour expression of leptin is associated with chemotherapy resistance and therapy-independent prognosis in gastro-oesophageal adenocarcinomas. Br J Cancer 110: 1525-1534, 2014.

12. Livak KJ and Schmittgen TD: Analysis of relative gene expression data using real-time quantitative PCR and the 2(-Delta Delta C(T)) Method. Methods 25: 402-408, 2001.

13. Delbridge AR and Strasser A: The BCL-2 protein family, BH3-mimetics and cancer therapy. Cell Death Differ 22: 1071-1080, 2015.

14. Mayer IA and Arteaga CL: The PI3K/AKT pathway as a target for cancer treatment. Annu Rev Med 67: 11-28, 2016.

15. Xia HH and Talley NJ: Apoptosis in gastric epithelium induced by Helicobacter pylori infection: Implications in gastric carcinogenesis. Am J Gastroenterol 96: 16-26, 2001.

16. Park MT, Kim MJ, Suh Y, Kim RK, Kim H, Lim EJ, Yoo KC, Lee GH, Kim YH, Hwang SG, et al: Novel signaling axis for ROS generation during K-Ras-induced cellular transformation. Cell Death Differ 21: 1185-1197, 2014.

17. Song IS, Oh NS, Kim HT, Ha GH, Jeong SY, Kim JM, Kim DI, Yoo HS, Kim CH and Kim NS: Human ZNF312b promotes the progression of gastric cancer by transcriptional activation of the K-ras gene. Cancer Res 69: 3131-3139, 2009.

18. Matkar SS, Durham A, Brice A, Wang TC, Rustgi AK and Hua X: Systemic activation of K-ras rapidly induces gastric hyperplasia and metaplasia in mice. Am J Cancer Res 1: 432-445, 2011.

19. Lee TI, Jenner RG, Boyer LA, Guenther MG, Levine SS Kumar RM, Chevalier B, Johnstone SE, Cole MF, Isono K, et al: Control of developmental regulators by Polycomb in human embryonic stem cells. Cell 125: 301-313, 2006.

20. Mongroo PS, Noubissi FK, Cuatrecasas M, Kalabis J, King CE Johnstone CN, Bowser MJ, Castells A, Spiegelman VS and Rustgi AK: IMP-1 displays cross-talk with K-Ras and modulates colon cancer cell survival through the novel proapoptotic protein CYFIP2. Cancer Res 71: 2172-2182, 2011.
21. Hanahan D and Weinberg RA: The hallmarks of cancer. Cell 100: 57-70, 2000.

22. Labi V and Erlacher M: How cell death shapes cancer. Cell Death Dis 6: e1675, 2015

23. Hensley P, Mishra M and Kyprianou N: Targeting caspases in cancer therapeutics. Biol Chem 394: 831-843, 2013.

24. Galluzzi L, Kepp O and Kroemer G: Caspase-3 and prostaglandins signal for tumor regrowth in cancer therapy. Oncogene 31 : 2805-2808, 2012.

25. Xue G, Zippelius A, Wicki A, Mandalà M, Tang F, Massi D and Hemmings BA: Integrated Akt/PKB signaling in immunomodulation and its potential role in cancer immunotherapy. J Natl Cancer Inst 107: pii: djv171, 2015.

26. Dibble CC and Cantley LC: Regulation of mTORC1 by PI3K signaling. Trends Cell Biol 25: 545-555, 2015.

27. Kawase T, Ohki R, Shibata T, Tsutsumi S, Kamimura N, Inazawa J, Ohta $\mathrm{T}$, Ichikawa $\mathrm{H}$, Aburatani $\mathrm{H}$, Tashiro $\mathrm{F}$ and Taya Y: PH domain-only protein PHLDA3 is a p53-regulated repressor of Akt. Cell 136: 535-550, 2009.

28. Worby CA and Dixon JE: Pten. Annu Rev Biochem 83: 641-669, 2014.

29. Li B, Wang L and Chi B: Upregulation of periostin prevents P53-mediated apoptosis in SGC-7901 gastric cancer cells. Mol Biol Rep 40: 1677-1683, 2013.

30. Hong SW, Jung KH, Park BH, Zheng HM, Lee HS, Choi MJ, Yun JI, Kang NS, Lee J and Hong SS: KRC-408, a novel c-Met inhibitor, suppresses cell proliferation and angiogenesis of gastric cancer. Cancer Lett 332: 74-82, 2013. 